\title{
Accessibility and Universal Design: Do They Provide Economic Benefits?
}

\author{
Alberto ARENGHI ${ }^{\mathrm{a}}$, Renato CAMODECA ${ }^{\mathrm{b}}$, Alex ALMICI $^{\mathrm{b} 1}$ \\ ${ }^{a}$ Department of Civil, Environmental, Architectural Engineering and Mathematics, \\ Università degli Studi di Brescia (Italy) \\ ${ }^{b}$ Department of Economics and Management, Università degli Studi di Brescia \\ (Italy)
}

\begin{abstract}
Certainly, the issue of accessibility has, in addition to a well-known social value, obvious economic repercussions. However, these are not easily measurable, as they can be investigated only on the basis of indicators that are mainly qualitative and indirect. That said, this paper will highlight some aspects that can be considered a first approach, identifying the variables and key players in the economic field.

The approach, according to the principles of Universal Design, already identifies economic implications related to the design of spaces, objects, and services. The socio-economic relevance has also been underlined within Sen's economic theories based on the capability approach and is generally referable to the theme of corporate social responsibility. In recent years, all this has been finding a universalistic synthesis in the enunciation of the Sustainable Development Goals.

The analysis is conducted according to an interdisciplinary qualitative approach from two main perspectives: the company and the public administration.

The study highlights how accessibility - understood according to a broad meaning that considers material and immaterial factors - assumes significant economic value with different specificities, depending on the reference actor (company/public administration).

In particular, it is evident that for the company, the issue of accessibility (both with regard to products and services and organizational profiles) is taking on an increasingly important dimension with reference to marketing and ratings.

The present work defines with clear evidence the main areas in which the economic value of accessibility appears, although a more in-depth study is needed to define metrics useful for quantifying the phenomenon. The study can be useful in various public and private sectors that involve policy-makers, designers, managers, and companies that produce goods and services.
\end{abstract}

Keywords. Universal Design, Corporate social responsibility, Public and private sectors, Economic value, Accessibility.

\section{Introduction}

An analysis of the recent international documentation ${ }^{2}$ — without dividing the population into groups or niches, but considering it entirely - makes clear that the social dimension

\footnotetext{
${ }^{1}$ Corresponding author, Department of Economics and Management, Università degli Studi di Brescia (Italy); E-mail: alex.almici@unibs.it.

${ }^{2}$ Among the others, see the UN Agenda 2030 [1], Habitat III [2], UN Convention on the Rights of Persons with Disabilities [3].
} 
has been strongly enhanced as a consequence of the shift in human rights from the individual to the collective.

With regard to the above statement, the accessibility issue has social implications due to the link between cultural and economic communities. These social implications are related mainly to the value-creation deriving from the choices of companies and public administrations to support the accessibility orientation based on careful consideration of the characteristics of all people. In this regard, the inclusion principles of Universal Design are, actually, combined with the economic paradigm identifying companies as "social-economic actors" and implying a wider notion of value. In this paper, the notion of value refers to different dimensions (economic and not economic) whose assessment requires the use of new metrics and techniques different from the traditional ones.

The analysis was developed on the basis of assessing the effects of improving accessibility conditions using different, complementary approaches, including the capabilities approach, the cost and benefit analysis, and measurement of the economic effect of the social impacts of specific activities.

The accessibility notion underlined in the paper is linked in economic terms to the choices about the inclusion of people with disabilities in the work environment, the production of goods and services according to Universal Design, and the availability of places that are easily accessible. These choices are all based on the shared idea that accessibility may be an important source of many positive effects (economic and not economic), including the development of innovative processes, the strengthening of competitive positioning, the creation of reputational advantages, and the improvement of the community's well-being.

Assessment of the benefits enables a review of the traditional approach, which is based on the idea that implementing measures that support accessibility is an issue of extra costs only and omits the analysis of potential direct and indirect advantages.

\section{The economic value of accessibility and the key actors}

The concept of Universal Design expresses a design approach in favor of "all," reducing to a minimum the risk of excluding potential users. In this sense, the concept of Universal Design is linked to that of accessibility, whose meaning implies the possibility for each person to participate actively in the labor market according to their specific abilities and competencies without incurring any discrimination and to benefit from the spaces, products, and services available and necessary to satisfy human needs.

The concept of accessibility is based on the enhancement of each person's specific capabilities and the consequent creation of conditions aimed at reducing potential urban, cultural, productive, and technological constraints.

This definition of accessibility emphasizes the central role of human beings and underlines the relevance of two main dimensions: the "internal" or "organizational" one, which relates to the job environment, and the "external" one, which relates to the goods, services, and spaces available to the community.

Universal Design principles are a useful guide to promoting the achievement of economic benefits that are strongly based on accessibility, equity, and corporate social responsibility.

These two dimensions underline the main areas where the principles of Universal Design may contribute to creating economic value whose meaning is wider than that 
related to the so-called exchange value. Indeed, the concept of economic value refers to the capabilities of companies and public administrations to promote the abilities of all people in order to transform them using innovative processes. The development of activities that take into account all potential users supports the creation of economic advantages for both the companies and the community.

Indeed, the definition of Universal Design supports that belief. In 1998, Mace provided an economic view of this approach, arguing "[...] Universal design broadly defines the user. It's a consumer market driven issue. Its focus is not specifically on people with disabilities, but all people [...]" [4]. By analyzing the principles of Universal Design together with its definition, it is possible to prove that spaces, products, and services designed according to this approach do not include dedicated solutions but do promote the normality of the image, implying a good relationship between quality and price.

Mace had already underlined the economic effects of the Universal Design approach in the 1988 publication "Universal Design: Housing for the lifespan of all people" [5] in which, referring to the real estate market, he argued that the approach may imply economic benefits for builders, designers, furniture suppliers, owners, and tenants. In numerical terms, it is important to point out that people with disabilities usually live with people without disabilities; thus, accessible solutions may produce advantages for the community in general.

Identifying the internal and external dimensions enables the selection of the key actors who are in a position to improve the quality of people's lives: companies and public administrations. Accessibility related to companies is, in turn, linked mainly to two dimensions that are based on the relevance of human beings. First is the organizational dimension, which involves the opportunity for all people to work according to principles of equity, inclusion, and non-discrimination. The second dimension concerns the supply of goods and services easily usable by everyone. Regarding public administrations, the concept of accessibility focuses on the availability of accessible places.

\section{Literature review}

The Italian founders of the field of business administration held a broad orientation regarding the economic relevance of the social dimension which is the impact of economic factors on the community. Despite this, the accessibility issue has not attracted great interest from scholars of business administration. In this regard, one idea that has often prevailed is based on the following two beliefs: one is that accessibility is a subject for only non-economic analyses (urban, sociological, ethical, etc.), and the other is that accessibility implies only costs, without any opportunity to produce benefits.

In particular, the accessibility issue has been analyzed mainly at the international level and according to a dual approach. First is the "direct" approach, which regards specific fields, including urban transport [6], [7], [8], [9], [10], [11], the livability of residential environments, the removal of architectural barriers and Information \& Communication Technology [12]. The second approach is the "indirect" one, which involves opportunities for the autonomy of people who have disabilities.

Regarding the first approach, the international literature includes mainly studies from the social and urban perspectives and using cost and benefit analysis of the efforts to implement Universal Design [13], [14]. Most of these studies contain analyses 
conducted according to quantitative models, including micro-economic [15], [16], [17], [18] and mathematical ones [19].

The other field in which accessibility has been studied relates to the difficulties experienced by people with disabilities when accessing places or using products and services [20], [21], [22], [23]. Among these studies, some macro- and micro-economic analyses can be distinguished from others related to business administration, enabling assessment of the effects of those with disabilities on the economies of communities, nations, and the specific companies.

In particular, macro- and micro-economic analyses have aimed to verify the community costs of disability [24] and the socio-economic effects of greater accessibility of goods and services by people with disabilities [25]. More precisely, these studies demonstrate the following.

- The inclusivity of the job environment and the perception of disability are linked, as the creation of an inclusive approach reduces the self-perception of disability and the community costs [26], which benefits the entire economy.

- Disability implies relevant social costs [27], [28], [29], [30], [31], [32], [33], [34].

- Managing disability may provide an opportunity to create long-term success [35], [36], [37], [38].

- Disability has several interconnections with either national economic trends or specific macro-economic conditions (for example, unemployment) [39], [40], [41], [42], [43], [44].

From a managerial perspective, analyses have focused on the contributions that a person with disabilities may provide by working [45], [46], [47]. [35], [48], [36], [37]. In addition, the value created by better inclusion of those with disabilities has been studied by some Italian scholars [49], [50], [51], [52], [53], [54], [55].

\section{Methodology}

The analysis of accessibility may be developed according to the so-called capabilities approach, which was introduced by the economist Amartya Sen. This approach is based on the belief that a person's well-being is not measurable by the amount of resources available, but instead with reference to capabilities, which are the real opportunities to choose and act according to the diversity that exists among people.

According to the capabilities approach, the best accessibility conditions should ensure that everyone is able to choose freely from among a wide set of opportunities. In this approach, companies and public administrations are committed to promoting the best expression of people's capabilities as a source of economic benefit.

Thus, it is important to identify the main positive effects deriving from the efforts of companies and public administrations to improve the accessibility of products, services, job environments, and other places. To achieve the above-stated goal, the capabilities approach should be integrated with a specific methodology, the cost and benefit analysis, with the aim of identifying the potential economic effects of accessibility. This means that the investigation of accessibility issue requires the combination of two different perspectives: a qualitative one related to capabilities approach and a quantitative one identified by the cost and benefit analysis. Indeed, cost and benefit analysis allows the 
assessment of the advantages of a specific choice by comparing the relevant costs and benefits

In general, the costs and benefits of accessibility can be classified according to three aspects: to be expressed in monetary terms, to be measured and to be related directly to the accessibility issue.

Regarding the first aspect, it is possible to distinguish between monetary and nonmonetary costs and benefits. The monetary ones include, for example, the costs to train workers who have disabilities as they usually need special training according to the specific disability involved. The non-monetary costs include the specific personal benefits deriving from an inclusive work environment: increased self-esteem, satisfaction, and participation in community life, among others.

In terms of measurability, it is possible to identify measurable costs and benefits and non-measurable costs and benefits, the latter of which include, for example, improvements in general well-being due to an inclusive work environment and the reputational advantage accruing to companies that commit to providing accessible goods and services.

Finally, regarding the possibility of directly relating these costs and benefits to accessibility, it is possible to distinguish between direct costs and benefits and those that are indirect, which usually include unforeseeable side effects to the community and are difficult to measure.

The greatest difficulties in assessing the effects of accessibility relate to the nonmonetary effects, especially the indirect ones that apply to the community. To measure these effects, some new techniques have been developed, including the Social Return on Investment (SROI) [56] which is an indicator that aims to measure the economic effects of a socially relevant investment [57], [58], [59], [60].

\section{Results}

In the following sections, the analyses focus on the potential economic advantages of applying Universal Design, with reference to the two main dimensions: organizational and goods and services.

The results are identified according to the "capabilities" general framework and to the cost and benefit analysis as required by the multidimensional nature (economic and non-economic) of the accessibility issue.

\subsection{Organizational accessibility}

The concept of organizational accessibility is based mainly on the following two aspects:

- The identification of work as a way to fully express the person [61];

- The belief that work is a special productive factor because it is characterized by specific intangible components, including knowledge and soft skills.

Organizational accessibility can be studied with reference to the potential advantages, also economic, that derive from an inclusive culture whose effectiveness requires that job environments be designed according to the principles of Universal Design [62], [63], [64]. In this sense, the choices aimed at improving the inclusion of 
work environments may produce some costs and some positive effects, mainly intangible and difficult to measure.

The benefits for companies - mainly indirect and both monetary and non-monetary - refer to improving innovative capabilities and creating a more creative, motivating work environment.

Improved organizational accessibility is a factor that potentially increases a company's productivity. On one hand, it reduces conflict among employees and promotes motivation and participation in achieving the companies' goals. On the other hand, accessibility is a factor in adapting work places, consequently reducing obsolescence.

Thus, implementing Universal Design principles with respect to the organizational dimension implies economic effects, including increasing the company's profit margin, improving its financial situation, etc.

Positive effects of organizational accessibility may be also be identified with reference to public administration. In this case, the main benefits are the following: increased income and consequent tax revenue from the employment of people with disability; increased contribution payments by such people; increased demand for goods and services due to increased income; increased available time for the relatives of people with disability, who usually are their caregivers and who may be able to work more and produce more taxable income; decreased healthcare costs (hospital stay, drugs, rehabilitation) and welfare costs borne by the State; decreased costs of subsidies for specific disability conditions.

In addition to these benefits, organizational accessibility implies specific costs, including the following: training for workers with disability, which may cost more than for those without disability as specific disabilities (for example, intellectual, learning, physical disabilities) may require tailored training programs employing specific educational technologies; cost of potentially greater work absenteeism by specific workers due to physical conditions (for example, for frequent medical examinations, etc.); cost of welfare measures aimed at supporting specific groups of workers; costs for adapting workplaces to reduce accidents; costs to improve the information and technology system to enable inclusion.

\subsection{Goods, services, and places accessibility}

The Universal Design approach may produce significant economic effects regarding the supply of accessible goods, services (especially for companies), and spaces (specifically for public administration).

In particular, regarding goods and services, Universal Design is related to potentially providing products and services that are accessible by a greater number of people.

The main economic advantages for companies are technological, competitive, and reputational.

The goal of improving the accessibility of products and services implies that new solutions will be researched and developed to satisfy users with different abilities. Thus, accessibility promotes innovation aimed at improving the quality of life for everyone. Indeed, the aim of satisfying the needs of all people is an important factor that pushes innovation toward creating new products and services. In fact, the Universal Design approach supports the production of goods that can be differentiated from competitors' versions, potentially accruing economic advantages. 
In addition, Universal Design implies cost reduction, as it is more suitable to design considering the characteristics of all people rather than to adapt finished products, which costs more and is less effective. Attending to all types of people during the design process can positively affect competitiveness, as Universal Design products and services:

- Usually aim to satisfy the majority of market users;

- Are usable in a more intuitive way;

- Are better able to satisfy users' needs, as they are designed considering the abilities of all potential users.

Considering the above-stated aspects, the main competitive advantages of the Universal Design approach may be identified as:

- Increased market share due to the attention paid to the needs of all people;

- Strengthened competitive advantage via differentiation of products and services;

- Greater customer loyalty.

Companies that decide to invest in accessibility according to the principles of Universal Design express a clear orientation toward ethics and social responsibility and their related reputational benefits [65], [66]. Indeed, making the effort to ensure accessible products and services improves perceptions of the company's imagine by stakeholders (shareholders, workers, media, community, suppliers, state, customers, lenders, etc.), and has positive economic effects. In fact, the choice to invest in accessible products and services identifies the company's social commitment and attention to innovation and has the following potential advantages: increased customer loyalty; easier fundraising from financial markets; generally reduced risk.

Public administration may also receive relevant benefits from investing in accessibility according to the principles of Universal Design. The economic relevance of accessibility is supported by both national and international statistical data related to people with disability: the Organization for Economic Cooperation and Development states that $1.5 \%$ of GDP - as a worldwide average - is allocated to people with disability ${ }^{3}$, while the Italian National Institute of Statistics states that in 2016, the public expenditure for social services amounted to 7 billion 56 million euros ${ }^{4}$. These data emphasize the potential economic effects on the public system of measures taken to support accessibility.

Specifically, the economic effects of investments in accessibility by public administrations refer mainly to supplying services and designing public spaces according to the Universal Design approach in order to promote people's mobility and participation in the community. Supplying public services (transport, education, etc.) according to the principles of Universal Design supports opportunities for everyone to live independently and positively affects the community's well-being and general productivity. In fact, the efforts of public administrations to improve the accessibility of services and places may reduce so-called non-accessibility social costs, a category of costs that includes the negative effects borne by the community regarding the non-accessibility of places. These effects include decreased consumption, especially that unrelated to primary goods or services (for example, recreational); increased insurance and legal costs related to work accidents caused by barely accessible places; the costs for paying caregivers to support

\footnotetext{
${ }^{3}$ http://stats.oecd.org.

${ }^{4} \mathrm{http}: / /$ www.istat.it/comunicato-stampa.
} 
the mobility of people with disability; and the costs for drugs whose amounts could be reduced in the presence of greater physical activity.

The points above emphasize that the lack of investment in the accessibility of places and services implies the introduction of costs whose reduction would create benefits, including decreased public expenditures. In addition, other benefits may be identified, including greater incomes and cash flows for public administrations as direct effects of increased participation in social life (sports activities, etc.) and increased demand for goods and services. These benefits are usually greater than the related costs, for example, those to remove urban barriers, to adapt work environments, etc.

\section{Conclusion}

The analysis underlines how the principles of Universal Design may contribute to creating economic advantages. To obtain these advantages, both firms and public administrations can develop their activities - even if using different approaches - to improve accessibility and create economic benefits.

This evidence underlines the opportunity for policy-makers to analyze the economic implications of greater accessibility, including decreased public expenditures and increased tax revenues for public administrations and improved economic performances for firms.

Therefore, there is a need to develop new metrics and techniques to measure the economic effects of social-impact decisions, including those related to the Universal Design approach.

\section{Reference}

[1] UN, Transforming our world: the 2030 Agenda for Sustainable Development $(A / R / 70 / 1),(2015)$, New York.

[2] UN, New Urban Agenda. HABITAT III (A/RES/71/256), (2017), New York.

[3] UN, Convention on the Rights of Persons with Disabilities (UN-CRPD) (A/R/61/106), (2006), New York.

[4] R.L. Mace, (speech) Designing for the 21st Century: An International Conference on Universal Design, June 19, 1998, Hofstra University, Hempstead, New York, (Title and text edited by Jan Reagan for publication, August 1998).

[5] VV.AA., Universal Design: Housing for the lifespan of all people, U.S. Department of Housing and Urban Affairs Publication HUD-1156-PA, 1988.

[6] E. Beyazit, Evaluating Social Justice in Transport: Lessons to be Learned from the Capability Approach, Transport Reviews 31 (2011), 117-134.

[7] K. Lättman, L.E. Olsson, M. Friman, A new approach to accessibility - Examining perceived accessibility in contrast to objectively measured accessibility in daily travel. Research in Transportation Economics 69 (2018), 501-511.

[8] R. Deboosere, A.M. El-Geneidy, D. Levinson, Accessibility-oriented development. Journal of Transport Geography 70 (2018), 11-20.

[9] C. McCahill, Non-work accessibility and related outcomes. Research in Transportation Business \& Management, 29 (2018).

[10] W. Xu, L. Yang, Evaluating the urban land use plan with transit accessibility, Sustainability Cities and Society, 45 (2019), 474-485.

[11] G.R. Bivina, A. Gupta, M. Parida, Influence of microscale environmental factors on perceived walk accessibility to metro stations, Transportation Research Part D 67 (2019), 142-144.

[12] B. Vollenwyder, G.H. Iten, F. Brühlmann, K. Opwis, E.D. Mekler, Salient beliefs influencing the intention to consider Web Accessibility, Computers in Human Behaviour 92 (2019), 352-360.

[13] R. Nissim, Universal Housing Universal Benefits. Discussion paper on universal housing regulation in Victoria, Victorian Council of Social Service (2008). 
[14] T. Halbach, K.S. Fuglerud, On Assessing the Costs and Benefits of Universal Design of ICT. In: Petrie, H. et al., Universal Design 2016: Learning from the Past, Designing for the Future. IOS Press, 662-672.

[15] L. Lyche, A. Hervik, A cost efficiency approach to universal access for public transport for disabled people. Institute of Transport and Logistics Studies, Faculty of Economics and Business, The University of Sydney, (2001).

[16] F. Alonso, The benefits of building barrier-free: a contingent valuation of accessibility as an attribute of housing. European Journal of Housing Policy 2 (2002), 25-44.

[17] D. Federing, D. Lewis, Towards a Framework for Identifying and Measuring the Benefits of Accessibility. Discussion Paper n. 2017-03, International Transport Forum, OECD, (2017).

[18] M. Rebstock, Economic Benefits of Improved Accessibility to transport Systems and the Role of Transport in Fostering Tourism for All. Discussion Paper n. 2017-04, International Transport Forum, OECD, (2017).

[19] J.B. Odoki, H.R. Kerali, Santorini, F., An integrated model for quantifying accessibility-benefits in developing countries. Transportation Research Part A, 35 (2001), 601-623.

[20] B.A. Wright, (1960) Physical disability. A psychological approach. Harper \& Row Publishers, New York, US, 1960.

[21] S. Saugestad, Cases of disability in a social context. In: F.J. Bruun, B. Ingstad, Disability in a CrossCultural Perspective. Working paper n. 4, Department of Social Anthropology, University of Oslo, 1990.

[22] G. Vulliamy, R. Webb, Special Educational Needs: From Disciplinary to Pedagogic Research. Disability, Handicap and Society 8, (1993), 187-202.

[23] J. Grue, Disability and Discourse Analysis. Routledege, London, 1994.

[24] O. Scarpat, Economia e handicap. L'analisi costi-benefici dell'inserimento dei disabili nel mercato del lavoro. Unicopli, Milano, 1987.

[25] Deloitte, Study on the socio-economic impact of new measure to improve accessibility of goods and services for people with disabilities, European Commission, 2013.

[26] R.L. O'Brien, Economy and disability: labor market conditions and the disability of working-age individuals, Social Problems, 60 (2013), 321-333.

[27] E. Berndt, W. Crown, J. Kallich, S. Long, X. Song, G.H. Lyman, The impact of anaemia and its treatment on employee disability and medical costs. PharmacoEconomics, 23 (2005), 183-192.

[28] R. Wasiak, J. Kim, G. Pransky, Work disability and costs caused by recurrence of low back pain: longer and more costly than in first episodes, Spine, 31 (2006), 219-225.

[29] R. Romeo, M. Knapp, P. Tyrer, M. Crawford, P. Oliver-Africano, The treatment of challenging behaviour in intellectual disabilities: cost-effectiveness analysis. Journal of Intellectual Disability Research, $\mathbf{5 3}$ (2009), 633-643.

[30] J. Perry, D.G. Allen, C. Pimm, A. Meek, K. Lowe, S. Groves, D. Cohen, D. Felce, D. Adults with intellectual disabilities and challenging behaviour: the costs and outcomes of in and out of area placements. Journal of Intellectual Disability Research, 57 (2003), 139-152.

[31] D. Felce, D. Cohen, P. Willner, J. Rose, B. Kroese, N. Rose, J. Shead, A. Jahoda, P. Macmahon, C. Lammie, A. Stimpson, C. Woodgate, D. Gillespie, J. Townson, J. Nuttall, K. Hood, Cognitive behavioural anger management intervention for people with intellectual disabilities: costs of intervention and impact on health and social care resource use. Journal of Intellectual Disability Research, 59 (2015), 68-81.

[32] G.S. Sagoo, S. Mohammed, G. Barton, G. Norbury, J.W. Ahn, C.M. Ogilvie, M. Kroese, Cost effectiveness of using array-CGH for diagnosing learning disability, Applied Health Economics and Health Policy, 13 (2015), 421-432.

[33] D. Generaux, N. Bansback, P. Birch, Development and pilot testing of a tool to calculate parental and societal costs of raising a child with intellectual disability, Journal of Intellectual and Developmental Disability, 41 (2016), 11-20.

[34] M. Pennington, E. Prince, N. Bateman, J. Gray, T.J. Croudace, M. Redley, N. Wood, H. Ring, Factors influencing the costs of epilepsy in adults with an intellectual disability, Seizure, 21 (2012), 205-210.

[35] Z.W. Oberfield, Accounting for time: comparing temporal and atemporal analysis of the business case for diversity management, Public Administration Review, 74 (2014), 777-789.

[36] M. Janssen, P. Zanoni, Alternative diversity management: organizational practices fostering ethnic equality at work, Scandinavian Journal of Management, 30 (2014), 317-331.

[37] C.M. Lu, S.J. Chen, P.C. Huang, J.C. Chien, Effect of diversity on human resource management and organizational performance, Journal of Business Research, 68 (2015), 857-861.

[38] I. Labucay, Diversity management and performance: paving the way for a revised business case, European Journal of International Management, 9 (2015), 425-441.

[39] X. Shang, Bridging the gap between planned and market economies: employment policies for people with disabilities in two Chinese cities, Disability and Society, 15 (2000), 135-156.

[40] J.L. Twigg, The cost of illness, disability, and premature mortality to Russia's economy, Eurasian Geography and Economics, 46 (2005), 495-524. 
[41] K.G. Manton, V.L. Lamb, X. Gu, Medicare cost effects of recent U.S. disability trends in the elderly: future implications, Journal of Aging and Health, 19 (2007), 359-381.

[42] P. Scullion, Economy and disability in Tokio and Manchester, International Journal of Therapy and Rehabilitation, 16 (2009), 522-523.

[43] N. Mehrotra, Disability, gender and caste intersections in Indian economy, Research in Social Science and Disability, 7 (2013), 295-324.

[44] M.T. Vincente-Herrero, M.J. Terradillos Garcia, M.V. De La Torre Ramirez Iñiguez, E. Aguilar Jiménez, L. Capdevila Garcia, A.A. López-González, The cost of temporary disability for headaches in Spain, Neurologia Argentina, 6 (2014), 199-206.

[45] M. Kulkarni, K.V. Gopakumar, Career management strategies for people with disabilities, Human Resource Management, 55 (2014), 83-107.

[46] U. Gensby, M. Labriola, E. Irvin, B.C. Amick, T. Lund, A classification of components of workplace disability management programs: results from a systematic review, Journal of Occupational Rehabilitation, 24 (2014), 220-241.

[47] L.F. Lara, E.A.R. de Campos, S.R. Stefano, S.M. de Andrade, Inclusion and diversity: a study of human resources management practices for people with disabilities, Espacios, 37 (2016).

[48] J. Burns, K.J. Euske, M.A. Malina, Debating diversity in management accounting research. In: M.J. Epstein, Y.J. Lee, Advances in management accounting, 24, Bingley, Emerald; 2014.

[49] G. Metallo, P. Ricci, G. Migliaccio, La risorsa umana “diversamente abile” nell'economia dell'azienda. Torino, Giappichelli, 2009.

[50] S. Angeloni, L'aziendabilità. Il valore delle risorse disabili per l'azienda e il valore dell'azienda per le risorse disabili. FrancoAngeli, Milano, 2010.

[51] G. Migliaccio, L'handicap in un'economia armonica. In: Giampaoli, A. Per un'armonia dell'economia. Terre di Confine, Urbino, 2011.

[52] S. Angeloni, Il Disability Management Integrato. Un'analisi interdisciplinare per la valorizzazione delle persone con disabilità. Quaderno Monografico Rirea, n. 94 (2011), Roma.

[53] S. Angeloni, Integrated disability management: an interdisciplinary and holistic approach, SAGE, 3 (2013), 1-15.

[54] G. Migliaccio, The Disability Marketing and the Cultural "Product": Italian Experience and Propositions for International Contexts. In: L. Aiello, Handbook on Research on Management of Cultural Products: E-Relationship Marketing and Accessibility Perspectives. Igi global, Hershey, 2014.

[55] G. Migliaccio, Disability management and "glocalization" for an inclusive society. In: V. Dermol, E. Trunk, M. Smrkolj, Conference proceedings of MakeLearn and TIIM 2015 International Conference managing intellectual capital and innovation for sustainable inclusive society. ToKnowPress, Bangkok, 2015.

[56] C. Clark, W. Rosenzweig, D. Long, S. Olsen, Double bottom line project report assessing social impact in double bottom line ventures, 2004.

[57] A. Bohmholdt, Evaluating the Triple Bottom Line Using Sustainable Return on Investment. Remediation, 2014.

[58] M. Moody, L. Littlepage, N. Paydar, Measuring Social Return on Investment, Nonprofit Management \& Leadership, 26 (2015).

[59] F. Owen, L. Jingyu, L. Whittingham, J. Hope, C. Bishop, A. Readhead, Social Return on Investment of an Innovative Employment Option for Persons with Development Disabilities, Nonprofit Management \& Leadership, 26 (2015).

[60] M. Walk, I. Greenspan, H. Crossley, F. Handy, Social Return on Investment Analysis, Nonprofit Management \& Leadership, 26 (2015).

[61] E. Zappella, I work so I am: the importance of work for people with disabilities. Rivista Formazione Lavoro Persona, 16 (2016), 92.

[62] M. Clermont-Ferrant, Handicap + impresa = Profitto e Progresso Sociale. Si Può. L'impresa, 3 (2005), 49-52.

[63] L. Rossi, Alcune esperienze di integrazione lavorativa di "diversamente abili” in azienda. In: G. Metallo, P. Ricci, G. Migliaccio, La risorsa umana "diversamente abile" nell'economia dell'azienda. Giappichelli, Torino, 2009

[64] O. Volpatto, Missione sociale ed equilibrio economico-finanziario delle cooperative sociali. In: G. Metallo, P. Ricci, G. Migliaccio, La risorsa umana "diversamente abile" nell'economia dell'azienda. Torino, Giappichelli, 2009.

[65] G. Hamel, C. Prahalad, The core competence of corporation. Harvard Business Review, may-june (1990).

[66] C.J. Fombrun, Reputation, Harvard Business School Press, Boston, 1996. 